
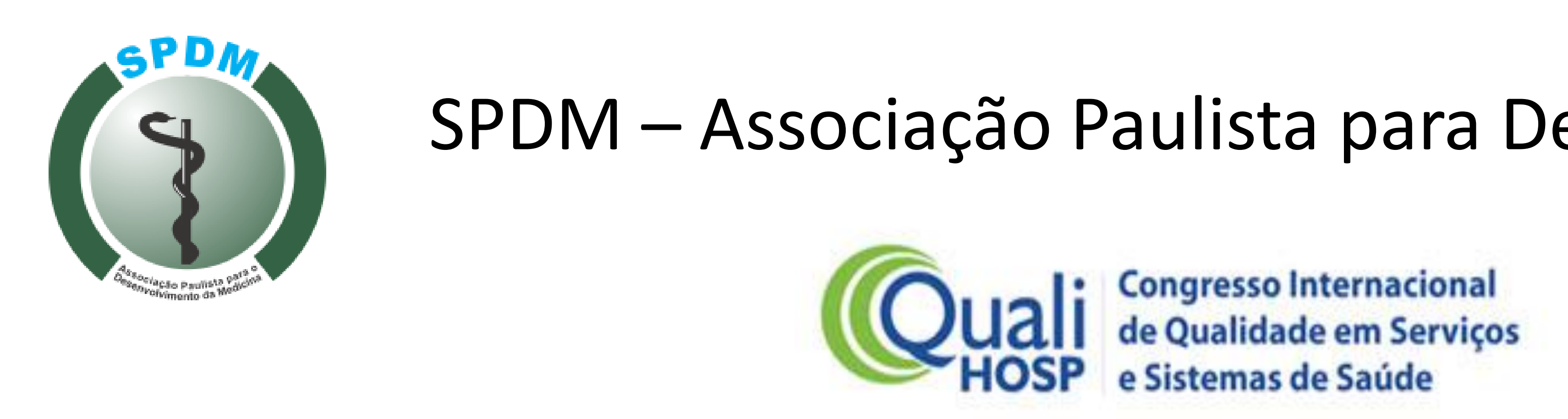

\title{
FGV EAESP
}

Ana Conceição de Lima Andrade, Patrícia do Prado Costa Braga, Gilmara Furtado Reis Penteado Roseli Gomes Cavalini, Sheila Pereira Mendes,

\section{EQUIPE REFERENCIA NA GESTÃO DE FLUXO EM PRONTO SOCORRO DE UM HOSPITAL PUBLICO DA GRANDE SÃO PAULO}

Eixo temático: Gestão em Saúde

INTRODUÇÃO: O grande fluxo de pacientes atendidos e a dinamicidade da rotina de um pronto-socorro (PS) fazem com que a atuação do enfermeiro precise ser eficaz, uma vez que é essencial. Os enfermeiros de PS são elementos fundamentais no processo de trabalho desse setor, não apenas ao realizarem o atendimento emergencial, mas ao atuarem efetivamente no gerenciamento da unidade, levando assim à melhor organização para sanar as necessidades de cada paciente. Vimos que a grande maioria dos hospitais públicos enfrentam o desafio de superlotação caracterizada pela ocupação máxima dos leitos disponíveis, pensando nesta alta demanda de atendimento, implantamos a equipe referencia na gestão de fluxo, onde uma equipe fica responsável pelos pacientes classificados como amarelo e outra equipe responsável pelos pacientes de classificação verde e azul.

JUSTIFICATIVA: facilitar e propiciar rapidez e agilidade no atendimento ao paciente além do estabelecimento de relação de confiança entre colaborador referência e paciente.

OBJETIVO: Reduzir o tempo para o atendimento ao paciente, fazendo com que seja visto precocemente de acordo com a sua gravidade otimizando seu atendimento e mitigando riscos de deterioração clínica.

MÉTODO: Trata-se de uma pesquisa de abordagem qualitativa do tipo descritivo-exploratória, realizado em um Pronto Socorro em um município de São Paulo, foram utilizados indicadores do ano de janeiro 2016 a setembro 2018.
RESULTADOS: Com a implantação da equipe de referencia no ano de 2017, o tempo de atendimento, incluindo a espera, foi de $4 \mathrm{~h} 22$ minutos em 2016, 3h em 2018; evidenciamos que houve uma redução de 1h22min. para o desfecho clínico com melhora progressiva e contínua dos resultados.

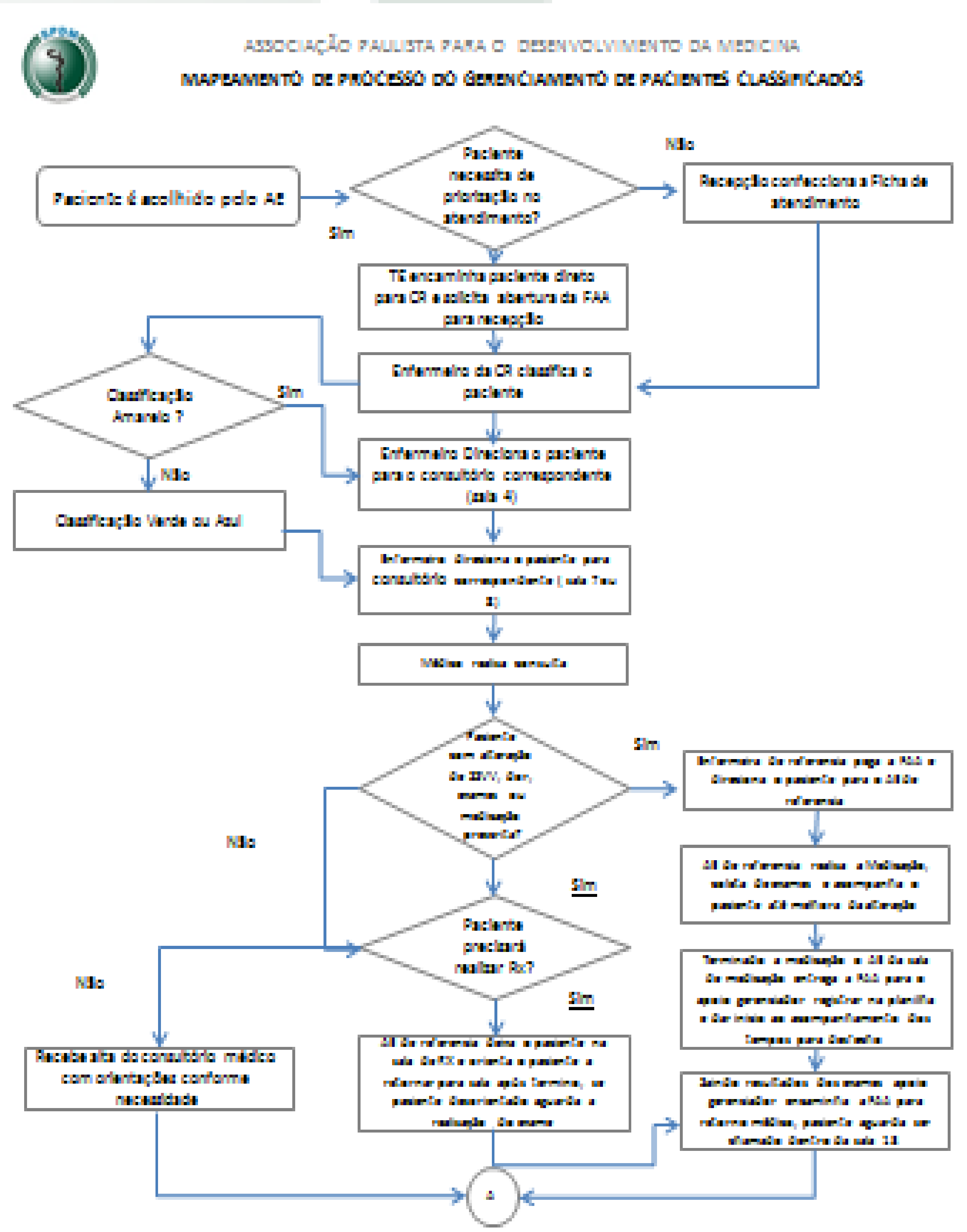

CONCLUSÃO: Verificamos que com a equipe referência implantada, conseguimos reduzir o tempo de atendimento ao paciente. 